\title{
Эволюция радиочастотных соединителей для мобильной и сотовой связи
}

\author{
К. Джуринский, к. т. н. ${ }^{1}$
}

УДК 621.37| ВАК 05.27 .01

\begin{abstract}
В сетях мобильной и сотовой связи используется множество радиочастотных соединителей, обеспечивающих передачу сигналов без искажения и потерь между базовыми станциями или удаленными антеннами. Продвижение вверх по частоте диапазонов связи и возросшие скорости передачи данных предъявляют все более жесткие требования к качеству высокочастотных трактов. Прежде всего, это относится к 5C - следующему поколению мобильной связи, где интермодуляционные искажения влияют на технические характеристики систем связи особенно сильно. В этой связи возрастают требования к радиочастотным соединителям. Рассмотрению современных радиочастотных соединителей для мобильной и сотовой связи посвящена данная статья.
\end{abstract}

\section{ТРЕБОВАНИЯ К РАДИОЧАСТОТНЫМ СОЕДИНИТЕЛЯМ \\ для МОБИЛЬНОЙ И СОтОвоЙ Связи}

Многие требования к радиочастотным соединителям для мобильной и сотовой связи такие же, как и ко всем другим соединителям:

- низкий уровень КСВН и прямых потерь в рабочем диапазоне частот;

- максимальные рабочее напряжение и допустимая пропускаемая мощность;

- высокий уровень экранного затухания;

- стойкость к механическим и климатическим воздействиям;

- большое число соединений и рассоединений вилки и розетки при минимальных усилиях

- большой срок службы;

- минимальные габаритные размеры и масса.

Кроме того, к соединителям для мобильной связи предъявляют и специфические требования:

- возможность наружного применения с высоким классом защиты IP 68;

- удобство эксплуатации, например возможность надежного соединения вилки и розетки без применения инструмента;

- низкий уровень интермодуляционных искажений.

Последнее требование является в настоящее время наиболее важным, так как уровень интермодуляционных составляющих спектра сигнала - критический параметр, влияющий на качество систем связи. Интермодуляционные составляющие возникают на нелинейностях высокочастотных трактов при прохождении по ним

АО «НПП «Исток»им. А.И. Шокина», kbd.istok@mail.ru сложных сигналов, имеющих несколько несущих частот В зарубежной литературе для интермодуляционных составляющих спектра сигнала принято обозначение IMP (Inter Modulation Products)

Наличие IMP может приводить к интермодуляционным искажениям сигнала - к ухудшению отношения сигнал/ шум. Наибольшие неприятности системам связи причиняют интермодуляционные составляющие низких нечетных порядков - 3-го и 5-го, поскольку они располагаются ближе всего к несущим частотам. При этом общепризнанным критерием является уровень интермодуляционных составляющих 3-го порядка (IMP3), имеющий наибольшую величину [1].

Интермодуляционные искажения в системах связи возникают при следующих условиях [2]:

- достаточно высокой мощности передаваемого сигнала;

- высокой чувствительности приемного устройства;

- наличии сложных сигналов, либо нескольких каналов передачи в единой полосе частот;

- использовании одной антенны для приема и передачи сигналов;

- наличии нелинейности в пассивных компонентах высокочастотного тракта.

Приблизительно в начале 1990-х годов интермодуляционные искажения в пассивных компонентах сотовой связи еще не были большой проблемой, поскольку уровни искажений были значительно ниже уровня шума самих устройств. Развитие базовых станций мобильной Связи GSM, DCS1800, PCS1900, а также широкополосной связи нового поколения выдвинуло жесткие требования к уровню ІМР для всех применяемых компонентов, в том числе и радиочастотных соединителей [2]. 


\section{Основные причины возникновения ІМР в соедини-} телях.

- Во-первых, состояние поверхности в области контактирования (неровности, микротрещины, различные дефекты).

- Во-вторых, коррозия. Кроме окислов на поверхности металлов присутствуют влага, пыль, органические загрязнения и остатки солей металлов после операций химического травления и осаждения покрытий. Они также представляют собой некоторую нелинейность.

- в-третьих, слабое усилие контактирования и ненадежный точечный контакт разнородных металлов.

- В-четвертых, наличие магнитных материалов и покрытий [1].

Поэтому для изготовления соединителей для мобильной и сотовой связи применяют только немагнитные материалы: латунь, бериллиевую и фосфорную бронзу. Для покрытия поверхности соединителя широко используется «белая бронза» - немагнитный коррозионно-стойкий и износостойкий сплав меди, олова и цинка и серебро. Предъявляются высокие требования к точности изготовления и чистоте поверхности соединителей, а также к усилию контактирования вилки и розетки при их сочленении

Уровень интермодуляционных искажений в таких соединителях не должен превышать (-160) дБс при входной мощности каждого из двух сигналов 43 дБм (20 ВТ).

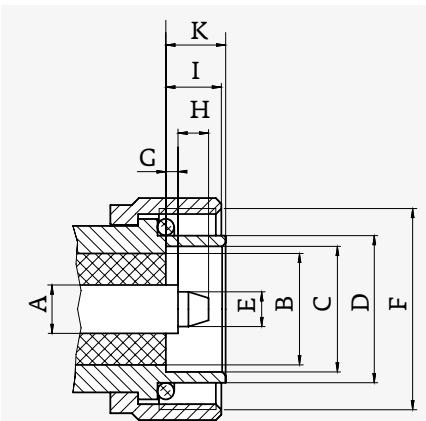

a)

\begin{tabular}{lcc} 
Обозначение & Размеры вилки, мм & Размеры розетки, мм \\
$\varnothing \mathrm{A}$ & 7,00 & 7,00 \\
\hline$\varnothing \mathrm{B}$ & $15,85-16,25$ & $15,85-16,25$ \\
\hline$\varnothing \mathrm{C}$ & $18,03-18,21$ & $17,84-18,02$ \\
\hline$\varnothing \mathrm{D}$ & $20,60-21,40$ & $22,10-22,90$ \\
\hline$\varnothing \mathrm{E}$ & $4,96-5,04$ & - \\
\hline $\mathrm{F}$ & $\mathrm{M} 29 \times 1,5$ & $\mathrm{M} 26 \times 1,5$ \\
\hline $\mathrm{G}$ & $1,47-1,77$ & $0,50-0,70$ \\
\hline $\mathrm{H}$ & 4,50 & $1,77-2,07$ \\
\hline $\mathrm{I}$ & $7,00-9,00$ & 8,10 \\
\hline $\mathrm{K}$ & $7,00-8,00$ & 10,00 \\
\hline
\end{tabular}

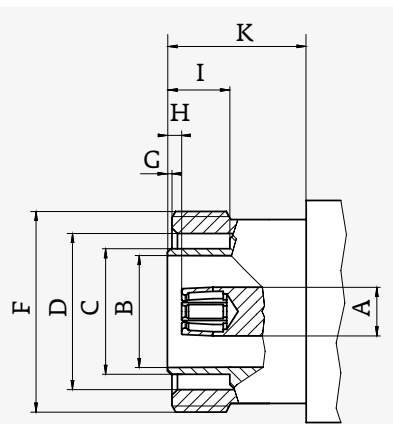

б)
Рис. 1. Интерфейс соединителя 7/16: вилки (а) и розетки (б) приведены в табл. 1.
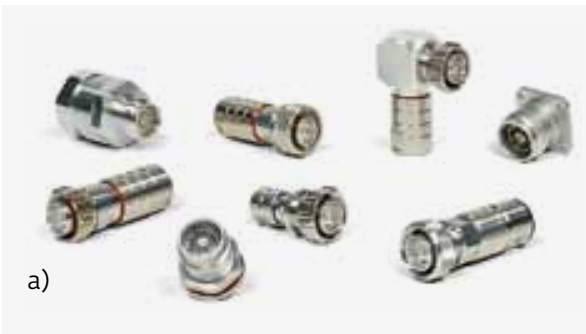

циях мобильной и сотовой связи. DIN (сокращение от Deutsches Institut für Normung) - это название Немецкого института по стандартизации. Многие стандартизованные коаксиальные соединители, разработанные немецкими компаниями, обозначались числами, которые означали диаметры внутреннего и наружного проводников коаксиальной линии соединителя.

История создания соединителя 7/16 началась в 1949 году, когда доктор Георг Шпиннер (Georg Spinner) из компании Spinner GmbH (Германия) разработал соединитель 6/16 с волновым сопротивлением 60 Ом [3]. В 1960-х годах была создана версия этого соединителя с волновым сопротивлением 50 Ом, которая была стандартизирована (стандарт Международной электротехнической комиссии - IEC61169-4) под названием 7/16 (7 и 16 мм - диаметры внутреннего и наружного проводников коаксиальной линии). Первоначально популярный в Европе, он получил широкое распространение в США и других странах.

Интерфейс вилки и розетки соединителя 7/16, согласно IEC61169-4, показан на рис. 1, а его внешний вид - на рис. $2[3,4]$.

Соединение вилки и розетки соединителей 7/16 резьбовое (резьба М $26 \times 1,5$ )

Технические характеристики соединителей 7/16 в сравнении с характеристиками соединителей других типов, применяемых в системах мобильной и сотовой связи,

Соединители 7/16 выпускают многие зарубежные компании: Spinner, Telegärtner, Rosenberger (Германия), Amphenol, Molex, (США), Huber+Suhner (Швейцария), Radiall (Франция), компании Юго-Восточной Азии.

Компании Spinner и Telegärtner разработали большое количество прямых и угловых кабельных соедини-

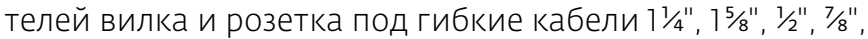
RG-58 / U, RG-223 / U, RG-303 / U, RG-142 / U, а также под полужесткие кабели RG-401 (0,250") и RG-402 (0,141"). Разработаны кабельные вилки под прижим, обжим и пайку кабеля в соединитель, фланцевые панельные розетки и выводы энергии (квадратный фланец размером 32×32 мм

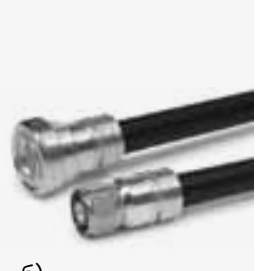

6)

Рис. 2. Соединители 7/16 (а) и кабельные сборки (б) 
с четырьмя крепежными отверстиями и межсерийные адаптеры и нагрузки). В кабельных сборках применяют гофрированный медный кабель спиральной навивки со вспененным диэлектриком (для уменьшения высокочастотных потерь).

Amphenol изготавливает соединители вилка и розетка для сборки с гофрированным медным кабелем. Панельные кабельные розетки снабжены прокладками из силиконовой резины для герметичной установки.

Huber+Suhner производит все типы кабельных соединителей с IMP3 на уровне (-165) дБс, КСВН менее 1,12 на частотах до 5 ГГц, экранным затуханием (-128) дБ, рабочим напряжением до 2,7 кВ и допустимой пропускаемой мощностью 1 кВт на частоте 2 ГГц. Кабельные соединители предназначены для сборки с медным гофрированным кабелем Sucofeed этой компании.

Radiall является одним из мировых лидеров в производстве соединителей типа 7/16 со сверхнизким (-168 дБс) уровнем интермодуляционных искажений. Кабельные соединители предназначены для сборки с гофрированным медным кабелем марки Celloflex.

Molex изготавливает соединители 7/16 с низким уровнем интермодуляционных искажений и потерями менее 0,15 дБ на частотах до 4 ГГц.

Соединители 7/16 широко применяют в многоканальных системах мобильной и сотовой связи, где особенно

Таблица 1. Технические характеристики соединителей для мобильной и сотовой связи

\begin{tabular}{|c|c|c|c|c|c|}
\hline \multirow[t]{2}{*}{ Параметры } & \multicolumn{5}{|c|}{ Тип соединителя } \\
\hline & $7 / 16$ & $4.3-10$ & $2.2-5$ & NEX10 & $1.5-3.5$ \\
\hline Волновое сопротивление, Ом & & & 50 & & \\
\hline Теоретическая предельная частота, ГГц & 8,3 & 13 & 26 & 21 & - \\
\hline Диапазон рабочих частот, ГГц & $0-7,5$ & $\begin{array}{c}0-12 \\
0-6 \\
\text { (оптимально) }\end{array}$ & $\begin{array}{c}0-20 \\
0-6 \\
\text { (оптимально) }\end{array}$ & $0-20$ & $0-30$ \\
\hline $\begin{array}{l}\text { Максимальный КСвН } \\
\text { (в диапазоне частот, ГГц) }\end{array}$ & $1,22(0-6)$ & $\begin{array}{l}1,03(0-4) \\
1,05(4-6)\end{array}$ & $1,05(0-6)$ & $\begin{array}{l}1,03(0-4) \\
1,05(4-6)\end{array}$ & $1,05(0-6)$ \\
\hline Прямые потери, дБ, на частоте f (ГГц) & 0,05 & 0,05 & 0,05 & 0,05 & - \\
\hline $\begin{array}{l}\text { Уровень ІМР3, дБс }(2 \times 43 \text { дБм }) \\
\text { в диапазоне частот, ГГц }\end{array}$ & -155 & $\begin{array}{c}\leq-166 \\
(0-4 \text { ГГц })\end{array}$ & $\begin{array}{c}\leq-166 \\
(0,4-4 \text { ГГц })\end{array}$ & $\leq-166$ & $\begin{array}{c}\leq-166 \\
(0-6 \text { ГГц })\end{array}$ \\
\hline $\begin{array}{l}\text { Максимальная пропускаемая } \\
\text { мощность, Вт (на частоте, ГГц) }\end{array}$ & $\begin{array}{l}1800(1) \\
850(2)\end{array}$ & $\begin{array}{l}700(1) \\
500(2)\end{array}$ & $\begin{array}{l}210(1) \\
150(2)\end{array}$ & $\begin{array}{l}140(1) \\
100(2)\end{array}$ & $100(2)$ \\
\hline Рабочее напряжение на уровне моря, кB & 2,7 & 1,8 & 1,0 & 1,4 & - \\
\hline Сопротивление изоляции, ГОм & $\geq 10$ & $\geq 5$ & $\geq 3$ & $\geq 5$ & - \\
\hline $\begin{array}{l}\text { Сопротивление контактов, мОм: } \\
\text { • центрального, } \\
\text { • наружного }\end{array}$ & $\begin{array}{l}\leq 0,4 \\
\leq 0,02\end{array}$ & $\begin{array}{l}\leq 1,0 \\
\leq 0,1\end{array}$ & $\begin{array}{l}\leq 2,0 \\
\leq 1,0\end{array}$ & $\begin{array}{l}\leq 1,5 \\
\leq 1,5\end{array}$ & - \\
\hline $\begin{array}{l}\text { Экранное затухание, дБ, } \\
\text { на частотах, ГГц }\end{array}$ & -128 & $\begin{array}{c}-110(0-6) \\
\text { (резьбовое } \\
\text { соединение) } \\
-90 \\
\text { (защелкивание) }\end{array}$ & $\geq-100$ & $\begin{array}{c}-110 \text { (0-6) } \\
\text { (резьбовое } \\
\text { соединение), } \\
\text {-70 (0-6) } \\
\text { (защелкивание) }\end{array}$ & - \\
\hline Усилие соединения вилки и розетки, Н & 15 & $\begin{array}{c}\leq 80 \\
\text { (защелкивание) }\end{array}$ & $\begin{array}{c}\leq 100 \\
\text { (защелкивание) }\end{array}$ & $\begin{array}{c}50 \\
\text { (защелкивание) }\end{array}$ & - \\
\hline $\begin{array}{l}\text { Усилие рассоединения вилки } \\
\text { и розетки, Н }\end{array}$ & 15 & $\begin{array}{c}\leq 60 \\
\text { (защелкивание) }\end{array}$ & $\begin{array}{c}\leq 80 \\
\text { (защелкивание) }\end{array}$ & $\begin{array}{c}\text { 35-40 } \\
\text { (защелкивание) }\end{array}$ & - \\
\hline $\begin{array}{l}\text { Допустимое количество соединений } \\
\text { и рассоединений }\end{array}$ & 500 & $\leq 100$ & $\leq 100$ & $\leq 100$ & $\leq 100$ \\
\hline Момент закручивания гайки, $\mathrm{H} \cdot \mathrm{M}$ & $25-30$ & 5 & 3 & $1,5-3$ & - \\
\hline Диапазон рабочих температур, ${ }^{\circ} \mathrm{C}$ & $-55 \ldots 155$ & $-55 \ldots 155$ & $-40 \ldots 85$ & $-55 \ldots 125$ & $-40 \ldots 85$ \\
\hline
\end{tabular}


недопустимы интермодуляционные искажения, в базовых станциях, антеннах суровнем мощности до 100 Вт на канал. Это самые прочные и надежные соединители, обеспечивающие высокую пропускаемую мощность и низкий уровень интермодуляционных искажений. До недавнего времени 7/16 являлся предпочтительным соединителем для антенн и базовых станций. Однако в связи с необходимостью миниатюризации соединитель 7/16 начал постепенно уступать свое место более миниатюрным аналогам.

\section{СОЕДИНИТЕЛИ 4.3-10}

Размеры и вес соединителей стали серьезной проблемой при создании новых систем мобильной и сотовой связи с высокой скоростью передачи данных. Потребность в соединителях с низким уровнем интермодуляционных искажений, меньшими размерами и весом для замены соединителя 7/16 была очевидна из-за необходимости миниатюризации оборудования мобильной связи. Начиная с 2012 года ведущие компании Spinner, Telegärtner, Rosenberger и Huber+Suhner объединили свои усилия и совместно разработали серию соединителей 4.3-10 для индустрии мобильной связи [3, 4]. Новая серия соединителей предназначена для улучшения технических характеристик оборудования мобильной сети при повышении его компактности и уменьшении занимаемой площади.

Внешний вид и размеры (при установке в ряд) соединителей 7/16 и 4.3-10 показаны на рис. 3 [4]. Соединитель 4.3-10 приблизительно на 40\% миниатюрнее и на 60\% легче соединителя 7/16. Это достигнуто за счет значительного уменьшения размеров коаксиальной линии соединителя 4.3-10. Важной конструктивной особенностью этих соединителей является разнесение плоскостей электрического и механического контактирования (рис. 4) [5]. Благодаря этому приблизительно на 80\% уменьшен момент затягивания гайки вилки и стало возможным соединение вилки и розетки без применения гаечного ключа. Кроме того, в отличие от осевого электрического контакта в соединителе 7/16, в соединителе 4.3-10 применен радиальный электрический контакт.

Предложенные конструктивные изменения позволили разработать три конструктивные версии вилки

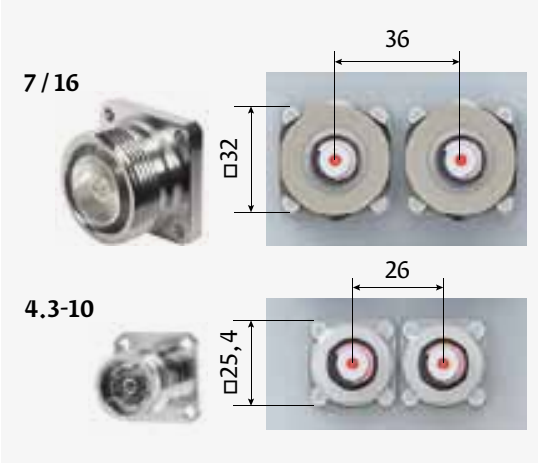

Рис. 3.

Внешний вид и размеры соединителей $7 / 16$ и $4.3-10$

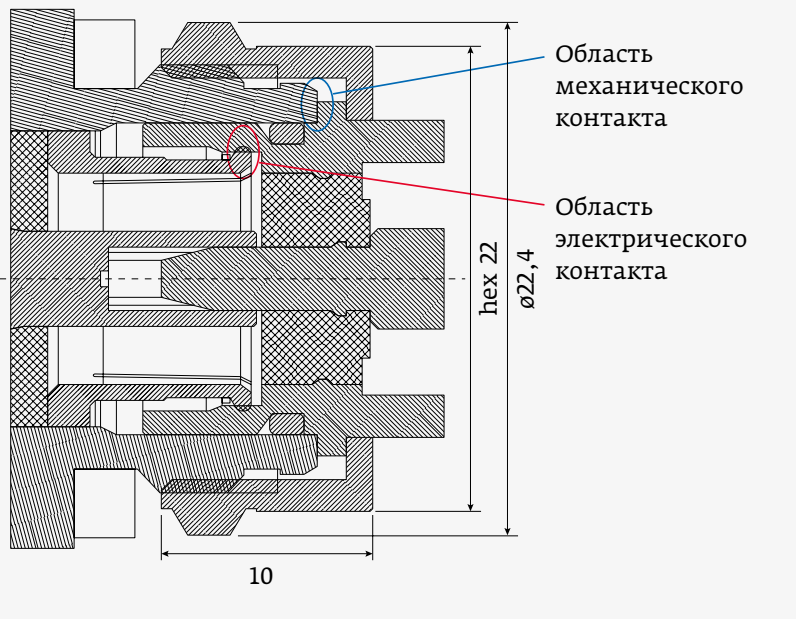

Рис. 4. Область контактирования соединителей 4.3-10

соединителя 4.3-10: с резьбовым соединением розетки и вилки при помощи динамометрического гаечного ключа (Screw type), с резьбовым соединением при закручивании вручную (Hand screw type) и с соединением защелкиванием (Quick lock, push-pull type) [3-7]. При этом для всех конструктивных версий вилки используется одна универсальная розетка (рис. 5) [6].

Резьбовое соединение кабельной вилки с розеткой при помощи ключа применяют для соединителей, работающих в условиях повышенных вибрационных и ударных нагрузок. При этом соединении недопустимо свободное вращение кабеля. Из-за высокого момента закручивания (5 Нм) соединение нечувствительно к раскручиванию под действием крутящего момента, приложенного к кабелю. Риск появления интермодуляционных искажений в таких соединителях минимален.

В соединителях с закручиванием вручную предусмотрено конструктивное решение против самопроизвольного раскручивания. Наконец, соединители с защелкиванием обеспечивают быстрое соединение без применения инструмента. При этом соединении возможно вращение кабеля после его заделки в соединитель. Соединения второго

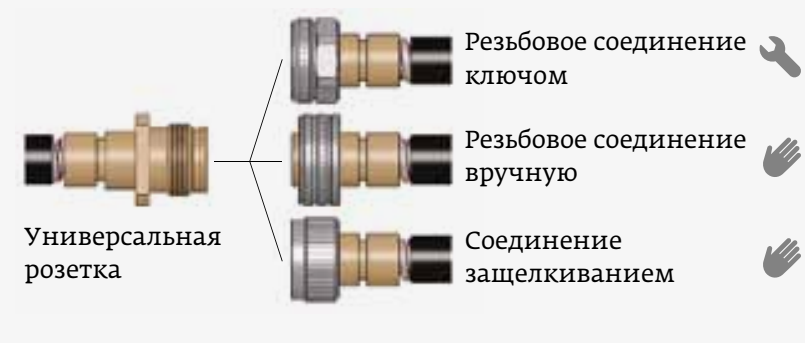

Рис. 5. Соединители 4.3-10 с разными механизмами сочленения розетки с вилкой 
Резьбовое соединение при помощи ключа

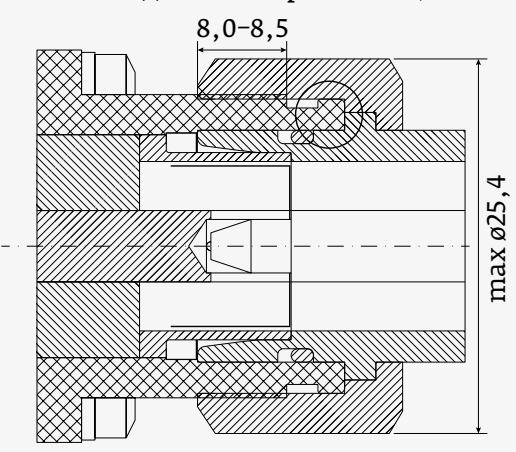

Резьбовое соединение вручную

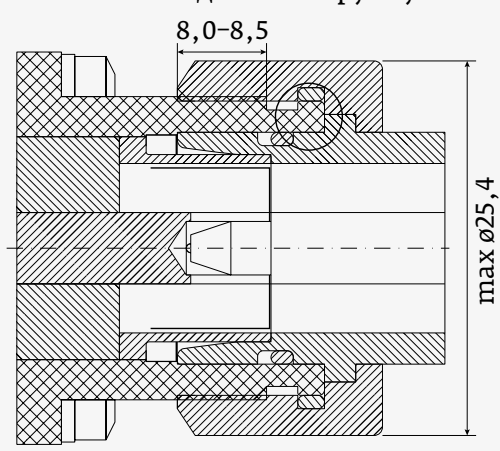

Соединение защелкиванием

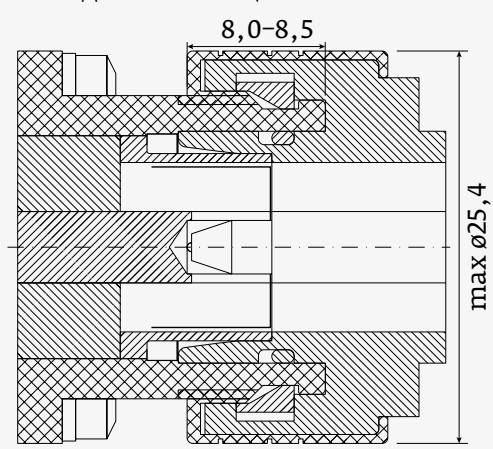

Рис. 6. Конструктивные версии соединителя 4.3-10

и третьего типов, не требующие применения гаечного ключа, обеспечивают более высокую плотность установки соединителей, например в антенны сотовой связи.

В 2016 году соединители 4.3-10 вошли в стандарт IEC61169-54. Интерфейсы соединителей этих трех типов показаны на рис. 6 [7].

Основные технические характеристики соединителей 4.3-10 приведены в табл. 1 [3-6].

Хотя стандарт МЭК 61169-54 устанавливает предельную рабочую частоту 6 ГГц, некоторые производители в своих data sheet гарантируют ее равной 12 ГГц.

Соединители 4.3-10 производят многие зарубежные компании Spinner, Telegärtner, Rosenberger, IMS, Amphenol, Molex, Huber+Suhner, Radiall и др. Номенклатура выпускаемых соединителей такая же, как и соединителей 7/16. Разработаны прямые и угловые кабельные соединители вилка и розетка под гибкие кабели 1\%"4", 15/8", 1/2", 7/8", RG-58 / U, RG-223 / U и кабели других марок, а также под полужесткие кабели RG-401 (0,250") и RG-402 (0,141"). Компании предлагают кабельные вилки под прижим, обжим и пайку кабеля в соединитель, фланцевые панельные розетки и выводы энергии (квадратный фланец 25,4×25,4 мм, с четырьмя крепежными отверстиями), внутрисерийные адаптеры под соединители розетка-вилка с разными типами рассмотренных выше вилок, а также межсерийные адаптеры [3-6].

Крупные западные компании Ericsson, Kathrein и Nokia Siemens Networks уже признали важность применения соединителей 4.3-10 в устройствах мобильной связи.

Область применения соединителей 4.3-10 варьируется от базовых станций до распределенных внутренних и наружных антенных систем (DAS).

\section{СОЕДИНИТЕЛИ 2.2-5}

Уже в настоящее время и особенно в будущем мобильные системы связи, жестко ограниченные по габаритным размерам и массе, должны передавать радиочастотные сигналы с малыми потерями и минимальными интермодуляционными искажениями. Поэтому, основываясь на успехе новаторского соединителя 4.3-10, компания Telegärtner в тесном сотрудничестве с компанией Spinner и с поддержкой компаниями Amphenol, Commscope, Molex, JMA Wireless и Gigalane разработала соединитель 2.2-5 с высоким уровнем параметров, более миниатюрный, чем соединитель 4.3-10 [8-10]. Размеры фланца фланцевого соединителя 2.2-5 меньше на 53\%, чем у соединителя 4.3-10, и на 70\%, чем у соединителя 7/16 (рис. 7) [9].

В соединителе 2.2-5 размеры коаксиальной линии были уменьшены в два раза (диаметр наружного проводника 5 мм, центрального проводника - 2,2 мм) по сравнению с соединителем 4.3-10 [9]. При этом сохранены особенности конструкции соединителей 4.3-10: разнесение плоскостей электрического и механического контактирования и радиальный контакт. Благодаря этому созданы кабельные вилки с резьбовым соединением с розеткой при помощи динамометрического гаечного ключа, с резьбовым соединением при закручивании вручную (на гайке имеется накатка для ручной затяжки) и с защелкиванием, какпоказано на рис. 5. Конструкция розетки универсальная и может соединяться с вилками всех трех вариантов исполнения [9].

К настоящему времени разработаны следующие соединители 2.2-5 (данные компании Spinner [10]):

- кабельные вилки под гофрированные кабели 1/4", 3/8", 1/2", а также под кабели RG-402 (0,141") и RG-401 (0,250");

- проходные панельные и фланцевые розетки под кабели RG-402 (0,141") и RG-401 (0,250"). Монтаж кабеля в соединители 2.2-5 выполняют пайкой, обжимом и прижимом;

- внутрисерийные и межсерийные адаптеры (для соединителей 4.3-10, 7/16, N)

Технические характеристики соединителей 2.2-5, по данным компании Spinner, представлены в табл. 1 [3, 10]. Несмотря на значительное уменьшение размеров, технические характеристики соединителей 2.2-5 и 4.3-10 


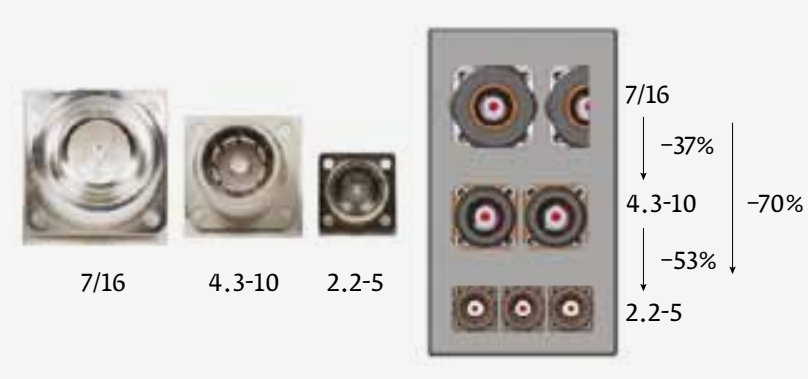

Рис. 7. Фланцевые соединители 7/16, 4.3-10 и 2.2-5

сопоставимы. Заявка на стандартизацию соединителей серии 2.2-5 представлена в МЭК в 2017 году.

\section{СОЕДИНИТЕЛИ NЕX10}

Конструктивные решения, реализованные в соединителях 4.3-10, стали основополагающими при создании в дальнейшем более миниатюрных аналогов этих соединителей. В связи с миниатюризацией оборудования сотовой и мобильной связи и повышением рабочего диапазона частот, антенны и приемники становились все меньше, и для них требовалось применение радиочастотных соединителей все меньших размеров. Соединители 4.3-10 с предельной частотой 12 ГГц уже не удовлетворяют этим требованиям, как по диапазону частот, так и по габаритным размерам и массе. Поэтому спустя всего лишь пять лет после создания соединителя 4.3-10 ведущие производители радиочастотных соединителей Rosenberger, Huber+Suhner и Radiall совместными усилиями разработали миниатюрные коаксиальные соединители NEX10 в диапазоне частот 0-20 ГГц для применения в небольших сотовых сетях 4С и 5С [11-14].

Интерфейс соединителей NEX10 был разработан с использованием опыта, накопленного при проектировании соединителей 4.3-10 и 2.2-5. Созданы кабельные вилки соединителя NEX10 двух вариантов: с резьбовым соединением при помощи динамометрического гаечного ключа и с соединением защелкиванием. Соединители NEX10 на 50\% миниатюрнее, чем 4.3-10, размер фланцев соединителей этих типов соответственно равны 25,4 и 12,7×17,4 мм (рис. 8а) [11]. Соединители NEX10 компании Rosenberger показаны на рис 86-г [12], интерфейс соединителей NEX10 - на рис. 9 [12]. Основныехарактеристики соединителей NEX10 по данным компании Rosenberger [12] приведены в табл. 1.

Разработаны следующие модификации соединителей NEX10:

- кабельные вилки под полужесткий кабель 0,141" и 1⁄4" три модификации;

- кабельные розетки проходные (две модификации) и панельные фланцевые (три модификации) под полужесткий кабель 0,141" и 0,085";

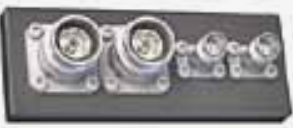

a)

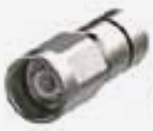

б)
Рис. 8. Фланцевые соединители 4.3-10 и NEX10 (a), соединители NEX10 компании Rosenberger: вилки с резьбовым соединением (б) и соединением защелкиванием (в), панельная фланцевая розетка (г)

- межсерийные адаптеры розетка и вилка NEX10 с соединителями N, 7/16, 4.3-10 и 3.5 mm.

Кабельные соединители NEX10 разработаны под обжим, прижим и пайку гофрированного кабеля 1/4" (для наружного применения) и кабеля 0,141" (RG-402) и 0,085" (RG-405) для применения в помещении

В 2019 году подана заявка в МЭК на стандартизацию соединителя NEX10. После стандартизации соединитель NEX10 станет доступным всем потребителям.

\section{СОЕДИНИТЕЛИ 1.5-3.5}

Разработка 5G - следующего поколения мобильной связи со скоростью передачи в 100 раз большей, чем 4G, создает новые, более сложные задачи для индустрии мобильной связи. Компания Telegärtner разработала

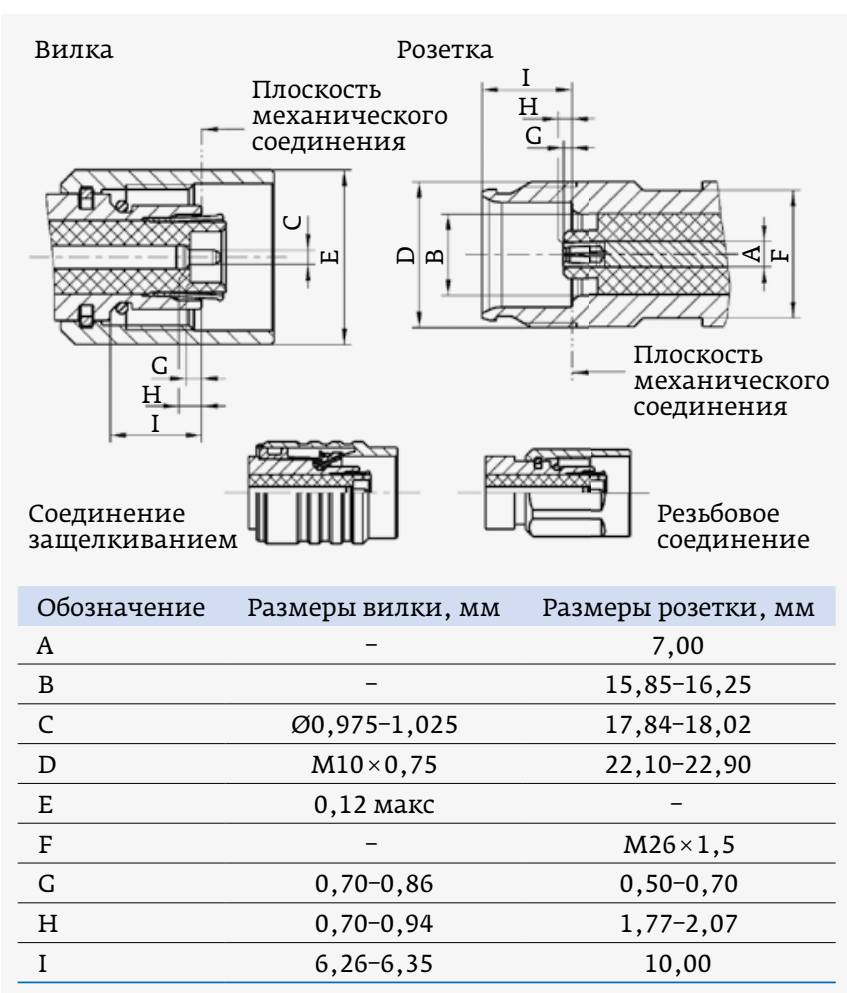

Рис. 9. Интерфейс вилки и розетки соединителей NEX10 


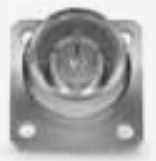

$2.2-5$

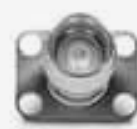

NEX10

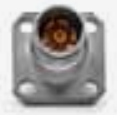

$1.5-3.5$
Рис. 10. Соединители

2.2-5, NEX10

и $1.5-3.5$ семейство соединителей Cell IQ, призванных решить проблему соединений в настоящее время и в будущем. Это семейство состоит из серий трех соединителей: 4.3-10, 2.2-5 и 1.5-3.5. Соединители 1.5-3.5 являются самыми миниатюрными из всех соединителей и предназначены для мобильной и сотовой связи будущего поколения. Размеры фланца с четырьмя отверстиями фланцевого кабельного соединителя равны 15×9,7 мм или 12,7×12,7 мм, что приблизительно на 47\% меньше, чем у соединителей 2.2-5, и на 75\% меньше, чем у соединителей 4.3-10 (рис. 10) [15-16].

Конструкция соединителя 1.5-3.5 такая же, как и у его предшественников, только коаксиальная линия выполнена с размерами 3,5/1,5 мм. По размерам коаксиальной линии этот соединитель сопоставим с соединителем $3.5 \mathrm{~mm}$ (SMA3.5), но выгодно отличается от него отсутствием интермодуляционных искажений и пригодностью для наружного применения

Созданы кабельные вилки 3-х вариантов с резьбовым соединением при помощи динамометрического гаечного ключа, резьбовым соединением вручную и соединением защелкиванием с ответной розеткой. Розетка универсальна и пригодна для соединения с вилками всех трех вариантов. Кабельные вилки прямые и угловые предназначены для работы с гофрированным кабелем 14", а также для кабеля UT 85, UT 141 и UT 250 Semiflex (рис. 11) [11].

Доступны также разнообразные адаптеры для работы с соединителями других серий: 4.3-10, 7/16, РС3.5 и N.

Технические характеристики соединителей 1.5-3.5 приведены в табл. 1. Так как предполагается работа сети 5G на все более высоких частотах, то предельная частота соединителя 1.5-3.5, равная 30 ГГц, выбрана не случайно. Возможен широкий спектр применений этих соединителей: сети мобильной радиосвязи, небольшие сотовые ячейки, маломощные удаленные радиоблоки, встроенные и распределенные антенные системы.

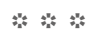

Соединители играют решающую роль в обеспечении высокого качества передачи радиочастотных сигналов между базовыми станциями и удаленными антеннами К ним предъявляются все более жесткие требования по уровню интермодуляционных искажений, величине потерь и габаритным размерам. Как показывает опыт, эффективность разработки соединителей для мобильной

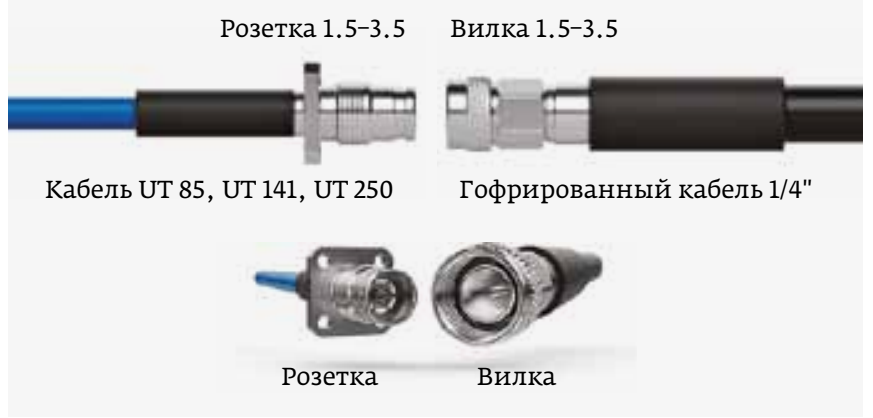

Рис. 11. Кабельные соединители 1.5-3.5

и базовой связи возрастает, если ее выполняет консорциум нескольких ведущих компаний. За рубежом менее чем за 10 лет были разработаны соединители 4.3-10, 2.2-5, NEX10 и 1.5-3.5 и налажено серийное производство их основных модификаций. Эволюция соединителей для мобильной и сотовой связи продолжается.

Автор выражает благодарность д. т. н. П. В. Куприянову за полезные замечания и М. В. Чебунину за предоставленные материалы.

\section{ЛИТЕРАТУРА}

1. Джуринский К. Б. Интермодуляции в радиочастотных соединителях // Компоненты и технология. 2010. № 6 . C. $26-30$

2. Kearney F., Chen S. Passive Intermodulation (PIM) Effects in Base Stations: Understanding the Challenges and Solutions. https://www.analog.com.

3. wwW.spinner-group.com.

4. www.telegärtner.com.

5. The new rf-interface for mobile communication. https://fhi.nl.

6. Why 4.3-10 connector is better than $7 / 16$ ? | orbis.eu https://www.orbis.eu.

7. 4.3-10 Connector. IEC61169-54.

8. Type 2.2-5 Coax Connector Fits in Tight Spaces | 2018-08-15. https://www.microwavejournal.com.

9. 2.2-5 Connector Series - Telegärtner https://www.telegärtner.com.

10. 2.2-5 Connectors - Spinner Group. https://www.spinner-group.com.

11. NEX10: Small, Robust and Low PIM RF Connector series. https://www.hubersuhner.com.

12. Nexl0-https://www.rosenberger.com/ 0_documents/de/specs/com/89-000-000.

13. Small Cell Connectors.2.2-5 or NEX 10. Каталог компании Spinner.

14. Radiall NEX10 Coaxial Connectors and Adapters. www.radiall.com.

15. 1.5-3.5 Series - Telegärtner https://www.telegaertner.com

16. New Coax Connector: Excellent Performance for Confined Spaces//Microwave Journal. 2019. September 12 


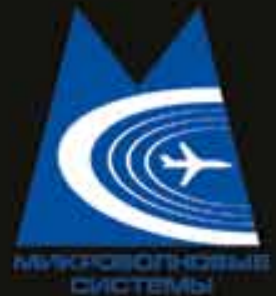

ИНТЕЛЛЕКТ. КАЧЕСТВО.

АО «МИКРОВОЛНОВЫЕ СИСТЕМЫМ Москва, Щелковское шоссе, А.5, стр.1 Ten. (499) 644-21-03, (499) 644-25-62 (многоканальный) Факс + 7(499) 644-19-70

E-mail:mwsystems@mwsystems.ru www.mwsystems.ru

- СОВРЕМЕННОЕ ПРОИЗВОДСТВО И ТЕХНОЛОГИИ

- OПТИМАЛЬHОЕ СООТНОШЕНИЕ ЦЕНА/КАЧЕСТВО

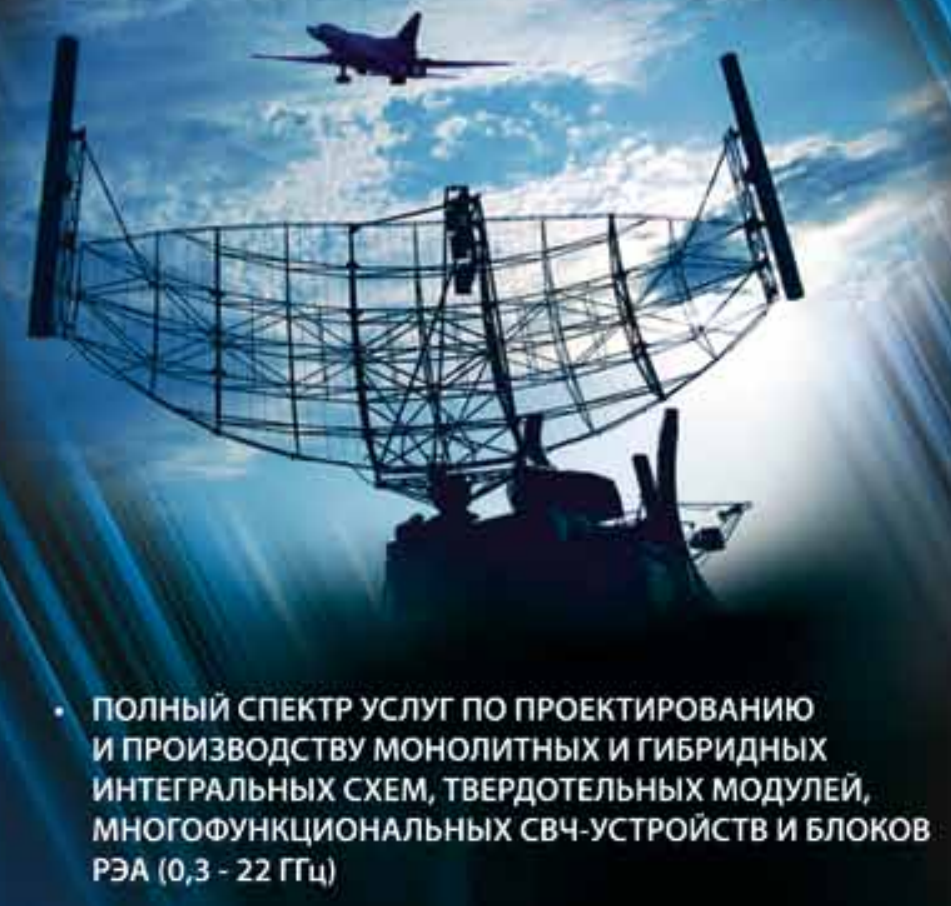

ПОЛНЫЙ СПЕКТР УСЛУГ ПО ПРОЕКТИРОВАНИЮ И ПРОИЗВОДСТВУ МОНОЛИТНЫХ И ГИБРИДНЫХ МНОГОФУНКЦИОНАЛЬНЫХ СВЧ-УСТРОЙСТВ И БЛОКОВ PЭA $(0,3$ - 22 TrL $)$

\section{АКЦИОНЕРНОЕ ОБЩЕСТВО «МИКРОВОЛНОВЫЕ СИСТЕМЫ"}
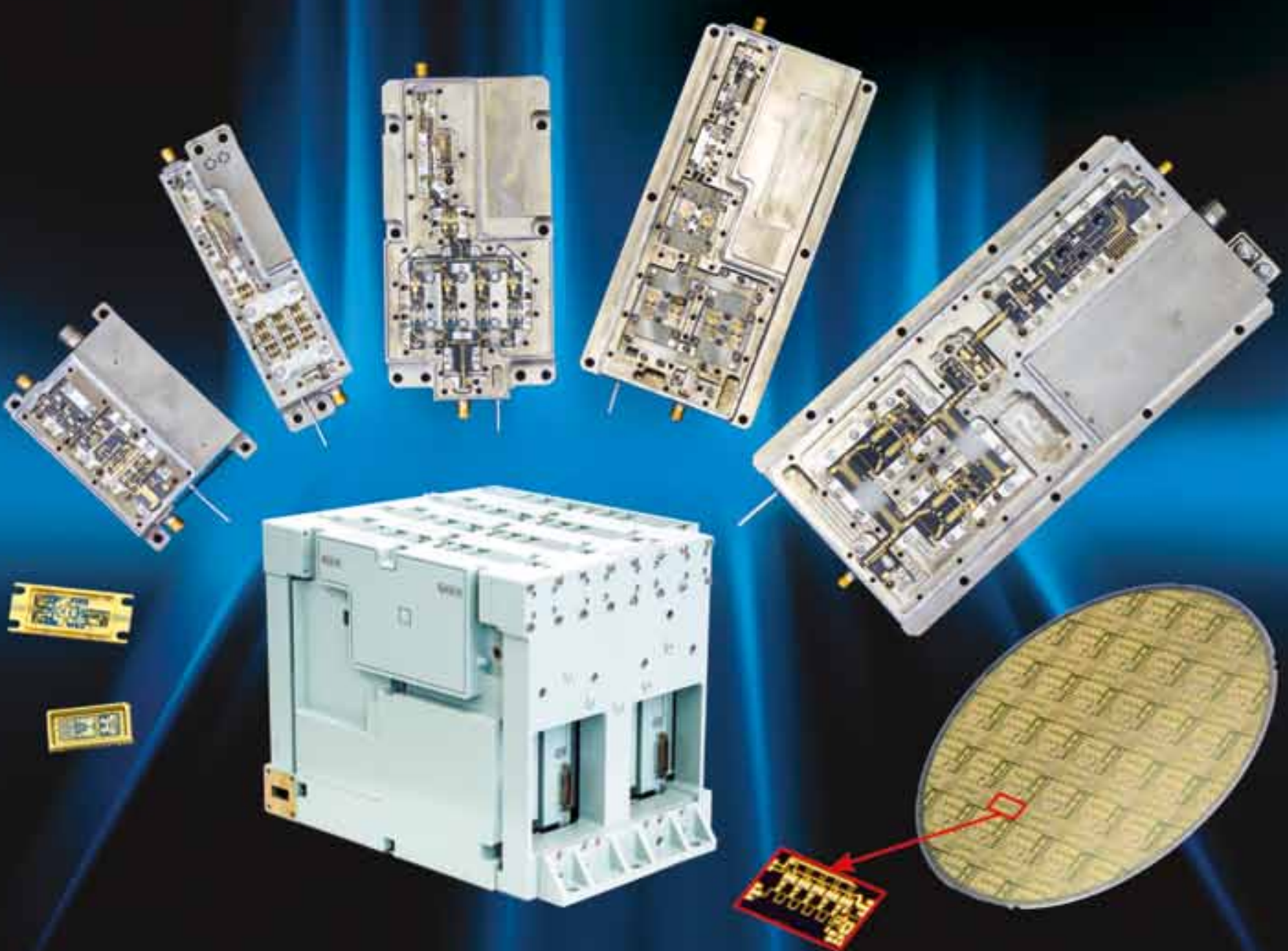